Session 2647

\title{
Attitudinal Aspects of Assessing Student Writing
}

\author{
Marilyn A. Dyrud \\ Oregon Institute of Technology
}

\begin{abstract}
For many instructors, regardless of academic field, evaluating student writing is a thankless task, one that requires a seemingly endless amount of time. Consequently, attitudes regarding assessment may be less than positive. This paper explores faculty attitudinal aspects of grading student writing by examining the results of a survey administered to engineering technology faculty at Oregon Institute of Technology, identifying concerns, and offering suggestions.
\end{abstract}

\section{Introduction}

Grading: it's the bane of many a teacher's existence. After a full day of teaching classes, organizing labs, answering student queries, attending committee meetings, and--just for good measure--working on a professional paper, that stack of student papers looms large at the edge of the desk. Less than joyous epithets arise at the thought of tackling this hours-long project. Furthermore, the excitement and enthusiasm of classroom interaction may pale when an instructor faces the written products of a student's thoughts. If, however, we can recognize and adjust our attitudes towards grading, that enthusiasm might re-emerge. This paper explains the results of a writing assessment attitude survey conducted at Oregon Institute of Technology, identifies areas of concern, and offers suggestions for improvement.

\section{The Survey}

In informal corridor and cafeteria conversation, faculty are not shy about expressing their discontent regarding student writing. As a communications instructor who has frequent contact with technical faculty, I decided to explore these complaints via a survey, in hopes of pinpointing areas of concern and offering suggestions that would help alleviate the frustration of technical faculty as they deal with the paper load. All 43 full-time engineering technology faculty were sent the "Writing Assessment Attitude Survey" (Appendix A), requesting demographic information, course data, and personal opinions on a variety of issues related to evaluating student writing. Of that number, 46.5\% (20) were returned. Not all respondents, however, answered all questions, and not all included a sample of graded student writing. Some of the questions also required multiple responses.

\section{Demographics}

Instructors queried represent all engineering technology programs offered at OIT (civil/surveying, mechanical/manufacturing, laser-optics, electronics, computer hardware and 
software). Their teaching experience totals a daunting 259 years, ranging from less than one year to 32 years. Of that aggregate, 169 years are at OIT, with service ranging from less than one year to 30 years.

Respondents are fairly equally distributed in rank; six are assistant professors, eight associate, and six full. Twelve are tenured, seven are on tenure track, and one is on annual contract.

\section{Course Data}

The survey asked faculty to select one of the courses they were currently teaching and respond to all questions based on that course. Courses were either lecture, lab, or a combination, and ranged from freshman to senior level, with a total enrollment of 278 students. In regards to writing frequency, half of the instructors indicated that students wrote less than once a week; six asked their students to write once a week, and only one required writing more than three times a week.

Students wrote a variety of papers, as indicated by Table 1 below. Most instructors apparently preferred assigning longer papers, requiring some sort of data-gathering, to shorter pieces.

Table 1. Types of writing assigned

\begin{tabular}{||l|c|c||}
\hline \multicolumn{1}{|c|}{ Type of document } & Raw number & $\begin{array}{c}\text { Percentage of } \\
\text { document types }\end{array}$ \\
\hline Letters & 3 & 15 \\
\hline Memos & 2 & 10 \\
\hline Technical reports & 10 & 50 \\
\hline Lab reports & 8 & 40 \\
\hline Term papers* & 4 & 20 \\
\hline Field notes & 2 & 10 \\
\hline Specifications & 2 & 10 \\
\hline Essay exams & 2 & 10 \\
\hline Other** & 2 & 10 \\
\hline \hline
\end{tabular}

* Research-based

** Includes math-based homework, design reports

All respondents graded all of the work their students submitted and used a variety of methods, indicated in Table 2. 
Table 2. Assessment methodologies

\begin{tabular}{||l|c|c||}
\hline \multicolumn{1}{||}{ Method } & Raw number & $\begin{array}{c}\text { Percentage of } \\
\text { methods used }\end{array}$ \\
\hline Circle errors & 15 & 75 \\
\hline Revise/edit & 8 & 40 \\
\hline Comments in margin & 16 & 80 \\
\hline Comments at end & 15 & 75 \\
\hline Seek outside input & 1 & 5 \\
\hline Peer review & 2 & 10 \\
\hline Other* & 1 & 5 \\
\hline
\end{tabular}

* Includes review with student

All of the respondents, except two, have either maintained or increased the amount of writing they assign. They offer the following rationales for their writing assignments:

- $\quad$ "It is important and nothing works like practicing."

- $\quad$ "Students need to know how to write concise, well structured documents."

- "It is so important for the students to write so I continue to assign it."

• $\quad$ "Because employers say our graduates are poor writers."

• $\quad$ "The students need more experience in writing, it is a critical skill!"

- $\quad$ " $[\mathrm{I}]$ think it's important for all students."

- $\quad$ I find it a valuable experience for students."

Faculty exhibit a range of attitudes (Table 3) when faced with a stack of papers to assess. 
Table 3. Faculty attitudes

\begin{tabular}{||l|c|c||}
\hline \multicolumn{1}{|c|}{ Attitude } & Raw number & Percentage \\
\hline Excitement & 6 & 30 \\
\hline Neutrality & 7 & 35 \\
\hline Resignation & 8 & 40 \\
\hline Depression & 3 & 15 \\
\hline Impatience & 3 & 15 \\
\hline Other* & 2 & 10 \\
\hline
\end{tabular}

* Includes "urgency" and "extreme interest"

Several ranked responses, noting initial enthusiasm at receiving the product and then resignation or depression during the actual grading session.

Time is a factor in attitude; most respondents indicated that grading is a time-consuming, and sometimes frustrating, venture: "If they wrote better, it would decrease the amount of time I spend grading"; "Not enough time to do what has to be done"; "It requires a large block of time, and I don't have enough." Others were more optimistic: "The students took the time to carefully organize and present their reports--the least I can do is give each report whatever time it takes to evaluate"; "This is too important to the students. I schedule the required time."

When estimating the amount of time faculty spent grading a set of papers, however, most reported spending only one to two hours for a class with 15 students; six indicated more than two hours and only one noted longer than that ("1-2 days").

\section{Personal Opinions}

Respondents were also asked for their opinions on a number of topics related to grading student writing. What faculty enjoy the most includes creativity, originality, individual growth and maturation, helping students improve their work, and reading good writing. Noted one instructor, "A well-turned sentence is a delight."

On the flip side, faculty dislike poor reports and view grading them as a waste of time, as indicated by the following comments: "If it is too bad, I tend to waste time editing it"; "difficult to be objective partially due to the time it takes to grade papers." Two instructors noted, with ironic spelling, that "gramar" [sic] and "slopiness" [sic] were problematic, and a number mentioned that some students seem to ignore past comments and repeat the same errors, resulting in evaluator impatience: "As I grade more papers I get frustrated at stupid mistakes." 
Most faculty feel that they are qualified to evaluate student writing, at least at the technical/content level. Some, however, have distinct reservations about their own grasp of mechanics and grammar: "qualified to evaluate the technical aspect. Less qualified on grammar aspect"; "I have trouble with punctuation--commas vs. semi-colons, etc. Technical content is the easy part"; "Grammar is not my strong suit"; "I feel qualified to evaluate the technical aspect and pseudo-qualified to evaluate grammar"; "Like many instructors in technical fields, I know bad writing when I see it, but I often feel at a loss as to how best to critique it."

\section{Concerns and Suggestions}

If survey results are reliable and truly reflect faculty opinions about evaluating student writing, several areas of concern emerge, some of which are easily addressed and others which involve more complicated solutions. These are detailed below:

\section{Goal Reconsideration}

Rethinking course and writing goals is a natural starting point and may result in improving the quality of papers instructors are reading. Here are some questions to consider:

- What is the purpose of the writing assignment? What will students gain? What will the instructor gain?

- Is the assignment necessary to meet course goals?

- What are the instructor's expectations of student writing? Can students access and understand grading criteria?

- $\quad$ Is class time devoted to discussing writing?

Writing has many purposes--to document a project, to propose a new or altered course or action, to record and/or analyze data, etc.--and students should understand both why they are writing and how that assignment relates to overall course goals. Groundwork laid carefully in class may prevent future misunderstandings. If all lab instructors, for example, would explain the purposes of a lab notebook--to document the experiment, to allow others to replicate the experiment, to provide original documentation if litigation occurs--more students might appreciate why their notes must be detailed and why they must not remove pages from their notebooks.

Clearly explaining criteria also helps orient students. Since it is difficult, if not impossible, to meet unknown expectations, preparing a "grading criteria" handout for students will help clarify instructor expectations. The criteria should clearly specify what constitutes an A, B, C, D, and F. And instructors, of course, must be conscientious is adhering to their own criteria.

It's also important to realize that students are not professional writers. They will have awkward 
sentences; they will make typing, spell check, and punctuation errors; they may have

organizational problems, especially at the freshman level. And they will not write like middleaged PhDs.

To help students succeed, it's essential to spend class time discussing the value of writing assignments as well as assignment content. Instructors who assign a complicated project the first week of the term and never refer to it again until the day before the deadline are setting up their students for failure and themselves for disappointment and frustration. Maintaining a file of the good, the bad, and the ugly will provide examples for class discussion. Models of goods writing are particularly important for students who have demonstrated writing difficulties or who lack initiative in consulting library resources. Students whose programs do not require technical writing courses or technical courses with a significant writing component may also benefit from a modeling approach.

With well articulated goals and criteria, class communication should improve, resulting in an enhanced learning atmosphere and more positive attitudes for both students and instructors.

\section{Time}

Attending to departmental, institutional, and professional obligations on top of a full teaching load is an interesting and complex juggling act. Adding the products of a writing-intensive course may require some creative scheduling.

However, is a lack of time really the problem? According to survey responses, most instructors spend about one to two hours per week per course grading papers, not an exorbitant amount of time, especially considering that half of the survey instructors do not require a weekly writing assignment.

To put the time issue in perspective, let's consider averages. Twenty faculty, with 278 total students, equals about 14 students per course. At two hours per week, this averages about seven minutes per paper. For the longer pieces of writing that these faculty members assign, seven minutes evaluation time is actually giving the students short shrift. That some faculty view this minimal time commitment as a problem is in itself unsettling.

The time issue, then, is more perceptual than actual: the thought of grading is more depressing rather than the actual process. And perhaps what makes the thought of grading depressing is the poor quality of writing. For most instructors, it's the poorly written papers, not the well written ones, which consume time and cause frustration. One way to reduce the time concern, then, is to improve writing quality. The rest of this paper will deal with the quality issue.

\section{Writing Assignments}

According to survey results, most instructors tend to assign longer pieces of writing, such as technical reports, which, of course, are more complex and time-consuming to grade. They are 
also more complicated for students to write. Yet only three instructors assigned shorter pieces, such as letters or memos.

Perhaps shorter pieces of writing will accomplish the same purpose and better suit the goals of the course. Documents such as abstracts, a series of short report memos, and annotated bibliographies are all valuable exercises and help keep students in the practice of writing. They also can be evaluated quickly, with minimal grading anxiety.

Some courses, such as senior capstone projects, require longer reports, and students certainly need to know how to write longer technical papers. But longer papers, of course, increase evaluation time. The following suggestions will help faculty cope with assessing long papers:

- Do not attempt to grade a whole set of papers at one sitting. Grade three or four and then do something else.

- $\quad$ Make evaluation criteria very specific.

- $\quad$ Return unacceptable papers, unevaluated, for revision.

\section{Assessment Techniques}

Another possibility is to reconsider grading practices. The survey indicates that most instructors use traditional methodologies, such as circling errors and writing comments. While these are "tried and true" techniques, they are also time-consuming, especially if instructors are actually editing and revising for students.

It is important to re-evaluate assessment goals: Is the purpose of evaluation to provide feedback? To prepare students for lives as professional writers, keeping in mind that engineers spend 50$80 \%$ of their time communicating in some formal fashion? ${ }^{1}$ To correct non-standard English? Each goal suggests a different assessment strategy. At times, it may not even be necessary to formally "grade" papers.

Prioritizing grading concerns can be helpful. Does everything in each paper require a comment? Students can be overwhelmed by comments, especially in regard to esoteric grammatical structures. A student who receives a paper covered with red ink will probably feel depressed, not enlightened. ${ }^{2}$ Joyce MacAllister's study does, in fact, offer compelling evidence that students react in inverse proportion to the number of comments they receive.

Not using formal grammar terms to identify writing problems can be a boon to both students and instructors. Though we may bemoan the fact, students today are not well schooled in the language of grammar and probably will not understand a comment regarding dangling modifiers. Instructors who feel hampered by a lack of terminology, and a number of survey respondents do, will feel liberated. A simple "I don't understand this sentence" is adequate.

Seeking outside input can also be useful. Talking to communications or English instructors, who evaluate pounds of papers annually, will yield techniques for rapidly and accurately assessing 
student writing, such as holistic assessment.$^{3}$ They probably do not circle errors and revise for students, using the rationale that the student is responsible to take care of grammatical etiquette details. Some even return non-standard writing, ungraded, several times for revision. Most English teachers will happily share their techniques and may even be willing to provide seminars for technical faculty regarding grading student writing. Several of the faculty surveyed indicated their interest in such a venture.

Outside consultants, experts in writing across the curriculum, can also share trade secrets; most are available for minimal honoraria, especially for ASEE-affiliated groups.

\section{Knowledge Transfer}

Students writing in technical classes are not writing in a vacuum or from lack of training; most are required to take formal writing courses at some time during their academic careers. At OIT, students take four writing classes (two in composition and two in technical writing), and it is not possible to pass these courses without exhibiting minimal proficiency in standard English. But what happens to the skills they learn?

The complaint registered by technical faculty about poor writing confirms the notion that students in technical courses place different value upon writing than when they are enrolled in communications courses. In short, the problem may not be bad writing but faulty knowledge transfer.

Technical faculty can assist in skill transfer by avoiding the temptation to give "split" grades, placing more emphasis on technical content than on writing style. What we write is how we write; a garbled lab report is no better, simply because it contains technical content, than a bad essay for an English course. Both are failed communication attempts. Giving content and style equal emphasis can help students understand that effective communication depends upon using standard English and conventional organizational patterns. And reading better student writing will, in turn, improve faculty attitudes.

We can also help in students skill transfer by reinforcing, in all courses, integration of knowledge. Writing doesn't only exist in the English department; nor does math end after differential equations. Although we have, to some extent, contributed to knowledge bifurcation by departmentalizing courses, students who are incensed that their instructor would actually grade writing style in a technical class have missed a major point of their technical writing course: that writing is not an entity of itself but exists within a clearly defined context.

\section{Conclusion}

Watching our students mature from gawky bubble-gum chewers into knowledgeable professionals is one of the true rewards of teaching; reading the output of their brains should be just as satisfying. As one survey respondent, with a dozen years of teaching experience, noted, "To review a good report is exciting." Our job as teachers extends far beyond inputting information into student heads. Our primary function, in fact, is to evaluate their output, in 
visual, verbal, and written forms.

Although following these suggestions will not end the grading anxiety which most instructors feel, they will help alleviate some of the pressures faculty experience. Writing is not a painless experience; nor is evaluating it. But we owe it to our students to approach the task in the best possible frame of mind, looking for success, not failure.

\section{References}

1. Beer, David and David McMurrey. A Guide to Writing as an Engineer. New York: John Wiley \& Sons, 1997.

2. MacAllister, Joyce. "Responding to Student Writing" in Teaching Writing in All Disciplines. Ed. C. Williams Griffin. San Francisco: Jossey-Bass, 1982: 59-65.

3. Dyrud, Marilyn A. "Holistic Grading: An Alternative Approach." Proceedings of the 24th Annual Frontiers in Education Conference, November 2-6, 1994, San Jose, CA: 721-3.

MARILYN A. DYRUD is a full professor in the Communications Department, Oregon Institute of Technology. She regularly teaches courses in business and technical writing, desktop publishing, and public speaking. She is active in ASEE as campus representative and contributes papers to the annual meeting. She is also active in the Association for Business Communication and the Association for Practical and Professional Ethics. 


\section{Appendix A: Writing Assessment Attitude Survey}

[Note: Please choose one of your courses this quarter for this questionnaire.]

\section{Demographic Data}

Number of years teaching:

Rank:

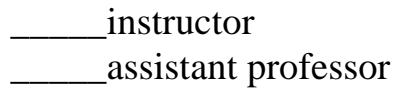

Tenure: annual not on tenure track
Number of years at OIT:

associate professor full professor

indefinite

\section{Course Data}

Type:

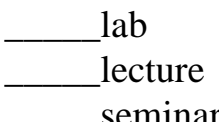

seminar
Level:

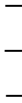

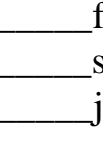
freshman (100) sophomore (200) junior (300) senior (400)

Enrollment: three times a week
more than three times a week ___ more than three times a week

less than once a week once a week twice a week

What do students write in this course? Check all that apply. Please indicate I (in-class) or O (outside class).

letters

memos

technical reports lab reports term papers (research)

field notes

lab notebooks other (please specify) manuals specifications essay exams

Do you assign grades to all written work your students submit? Please explain.

yes

no

When you receive a set of papers to grade, what is your initial reaction? (If more than one is applicable, please rank by number, with 1 being most dominant.)

excitement neutrality resignation depression anger impatience

other (please specify) 
Writing Attitude Survey

Page 2

How long do you generally spend grading a set of papers?

less than an hour

more than 2 hours

about an hour

other (please specify)

1-2 hours

Is time (as indicated above) a factor in your attitude?

yes Why?/Why not?

no

How do you typically assess a paper? Check all that apply.

circle errors

seek outside input

revise/edit

use peer review (student feedback)

make comments in margin

other (please explain)

write comments at end

If possible, please attach a copy of a student paper which you have assessed (and please remove the student's name).

What about grading student writing do you enjoy the most?

What about grading student writing do you dislike the most?

If you have been teaching for several years, have you increased/decreased/maintained the amount of writing you assign? Why?

Do you feel qualified to evaluate student writing? Please explain.

Other comments (add paper if necessary): 